\title{
A Novel Approach to Supply the Water Reservoir Demand Based on a Hybrid Whale Optimization Algorithm
}

\author{
Alireza Donyaii (D), Amirpouya Sarraf $(\mathbb{D}$, and Hassan Ahmadi $(\mathbb{D}$ \\ Department of Civil Engineering, Roudehen Branch, Islamic Azad University, Roudehen, Iran \\ Correspondence should be addressed to Amirpouya Sarraf; st.ar_donyaii@riau.ac.ir
}

Received 21 September 2020; Revised 2 November 2020; Accepted 15 November 2020; Published 2 December 2020

Academic Editor: Seyed Mahdi Seyed Kolbadi

Copyright (c) 2020 Alireza Donyaii et al. This is an open access article distributed under the Creative Commons Attribution License, which permits unrestricted use, distribution, and reproduction in any medium, provided the original work is properly cited.

\begin{abstract}
Managing water resources requires the optimum operation of dam reservoirs. To satisfy the downstream water demand in the operational optimization of Boostan dam reservoir, the improved whale optimization algorithm (IWOA) performance was compared in the present study with that of its constituents (i.e., the whale optimization and differential evolution) based on GAMS nonlinear programming results. The model evaluative indicators and an objective function were used to select the optimal algorithm. The findings suggested that IWOA resulted in the lowest computational duration and fastest convergence rate compared to the other algorithms. Additionally, the average water demand and discharge volume of IWOA were $3.21 \times 10^{6} \mathrm{~m}^{3}$ and $3.03 \times 10^{6} \mathrm{~m}^{3}$, respectively. In contrast, the other algorithms yielded lower water release volumes. IWOA enhanced the WOA performance by $21.7 \%$ through reducing the variation coefficient by $78 \%$ in optimizing the objective function. The water demand was therefore more effectively satisfied by the IWOA compared to the other algorithms. Furthermore, the IWOA resulted in a lower amount of errors. The hybrid algorithm performance increased in terms of all the evaluative indicators. Developing multicriteria decision-making models using TOPSIS and the Shannon entropy also suggested the IWOA excels the other algorithms in optimizing the reservoir operational problem.
\end{abstract}

\section{Introduction}

Managing water resources constitutes an essential domain in hydrological sciences for the sustainable utilization and allocation of valuable resources such as water [1]. Managers of water resources have identified water shortage as a globally major problem in various areas. This practical problem can be solved using state-of-the-art technology, innovative ideas, and strategic decisions made on water utilization [2, 3]. Water scarcity can also be solved through the operational optimization of reservoirs. Water resource policymakers therefore require appropriate optimization algorithms for lowering the difference between the demand for water and water discharge and generating optimal operation rules for water usage [4]. A reservoir operation is controlled mainly to reduce water shortage by developing the rules for the controlled discharge of water for downstream users [5]. The minimum permissible volume of the water stored in reservoirs in critical conditions and dry seasons must also be ensured [6]. Appropriate optimization algorithms should be therefore selected to take the necessary measures for the controlled discharge of water, provide various water users, including agricultural and industrial sectors, with a sustainable water supply, and therefore solve the operational problems of reservoirs $[7,8]$.

Metaheuristic and evolutionary optimization algorithms have been developed during the past 2 decades to solve complicated engineering problems. The main advantages of these methods include their simplicity of adjusting system constraints and objective functions within their mathematical domain. Obtaining a globally optimal solution can be, however, time-intensive, which is unacceptable in real-time operation. The computational time required by metaheuristic and evolutionary techniques for solving complicated problems has been demonstrated to be the least, making them an optimal choice for main decision-makers who need real-time solutions for their problems [4]. 


\section{Review of the Literature}

Genetic programming was applied by FallahMehdipour et al. [9] to a reservoir operation to decrease shortages of irrigation by considering the downstream discharge of water, the decision variable, and testing various mathematical and arithmetic operators for genetic programming. They found the demand for irrigation to be satisfied with the maximum reliability indicator compared to the reliability indicators of genetic algorithm and particle swarm optimization.

A case study was conducted in Iran by Ostadrahimi et al. [10] by applying particle swarm optimization to a multireservoir system to obtain various rule curves and decrease shortages of irrigation. The convergence rate of this new version of PSO was increased by making it function on the basis of a modified inertia weight. The data obtained were compared with those of nonlinear programming and genetic algorithm. The released water met the irrigation demand using particle swarm optimization, whose convergence was found to be faster than that of GA.

The reservoir operation was optimized and the benefits of power generation were improved by Afsahr [5] taking advantage of a modified particle swarm optimization adapted to hydraulic and hydrological boundary conditions of the problem in a way that the algorithm modeled the reservoir operation through a drought. The solution obtained using this version of particle swarm optimization was on average close to the globally optimal solution, and the power generated per year was higher than the power obtained using harmony search and genetic algorithm. Employing ant colony optimization to operationally optimize multireservoir systems helped satisfy the demand for irrigation with the minimum risk and minimize the average irrigation deficit [11]. Afshar and Moeini (2013) increased the diversity of the initial population by developing ant colony optimization on the basis of a mutation operator.

Genetic algorithm and novel dynamic programming proposed by [12] was applied to multireservoir operation to increase the power generated in China. Genetic algorithm outperformed dynamic programming despite the limited power generated in dry years, which required a rationing process. The position of drops was considered the initial population and a decision variable in the water cycle algorithm to reduce deficit in power based on the drop movements in the environment [13]. The running time of the water cycle algorithm was lower than that of genetic algorithm and particle swarm optimization, and this algorithm minimized the average deficit. A case study in Iran by Bozorg-Hadad et al. [14] was aimed at reducing power deficits using the bat algorithm based on surrounding frequencies received by bats. As a decision variable, the position of a bat was updated according to frequency and velocity. The rate of convergence of this algorithm based on random walk and local search was found to be higher than that of particle swarm optimization and genetic algorithm. Moreover, its power generation received a higher index of reliability.

Deficits in supplying demand for irrigation were minimized in a reservoir operation, and the released water obtained from a third-order nonlinear rule curve on the basis of genetic algorithm was found to satisfy irrigation requirements given the high reliability index obtained [15]. Biogeography-based optimization used in a case study in Iran to reduce deficits in power [16] on the basis of migration processes and habitats in the environment resulted in solutions that approached the globally optimal solution through fewer iterations. The simple algorithm process used an initial species population in the environment. Applying the weed optimization algorithm to increase power generation in a multireservoir operation by Asghari et al. [17] showed the superiority of this algorithm by convergence rate and generated benefits compared to the water cycle algorithm and genetic algorithm as well as particle swarm optimization.

Employing fixed length genetic programming to decrease the demand for irrigation in multireservoir operation [18] found this method to contribute to meeting the demand with a larger convergence rate than that of other algorithms and a higher reliability index than that of genetic programming. Utilizing the gravitational search algorithm to decrease power generation in a multireservoir system [19] suggested the need of this algorithm for accurate analyses of sensitivity to its random parameters. In comparison with particle swarm optimization and genetic algorithm, this algorithm resulted in a higher power generated annually and a larger convergence rate. Applying the shark optimization algorithm to reservoir operation demonstrated the effectiveness of this algorithm in satisfying the demand for irrigation with a larger convergence rate and index of reliability than those obtained from particle swarm optimization or genetic algorithm [20]. Applying monarch butterfly optimization by [5] Ehteram et al. [8] to multireservoir operation in China based on a migration operator for the butterflies showed increases of $14 \%$ and $12 \%$ in the average annual power generation than that of particle swarm optimization and genetic algorithm, respectively.

A case study by Mousavi et al. [21] using the crow algorithm for extracting rule curves to manage irrigation on the basis of the potential of crows for finding and hiding foods showed significant decreases in the vulnerability index. The average annual deficit in irrigation obtained by applying the krill algorithm to irrigation management and reservoir operation by Karami et al. [22] using the initial krill's position as the decision variable, respectively, decreased by of $20 \%$ and $23 \%$ compared to the deficit of the particle swarm and genetic algorithms. Applying the kidney algorithm based on the kidney function in the body to a reservoir operation to decrease power generation [23] showed that the kidney algorithm provided the best performance against the other evolutionary algorithms. It was stated that the KA achieved the first rank for the optimization problem and, thus, it showed a high potential to be applied for different problems in the field of water resources management.

The authors of [24] developed the Multiobjective Grey Wolf Optimization (MOGWO) algorithm to obtain the optimum rules on the operation of the Golestan Dam in Golestan province, Iran, under the climate change 
conditions. Their results showed that the river flow would decline by 0.17 percent of the baseline period under climate change conditions in addition to increasing the temperature by $20 \%$ as well as decreasing the rainfall by $21.1 \%$. In another research in the same year, they studied the Multiobjective Farmland Fertility Optimization (MOFFA) algorithm to derive optimum rules on the operation of the Golestan Dam under climate change conditions. The study results indicated an increase in release rates for climate change conditions in comparison with the baseline ones and stronger dam efficiency in climate change conditions [25].

\subsection{Study Objectives, Novelty, and Problem Statement.} Great potential for solving water resources management problems has been reported for evolutionary algorithms. Recently developed hybrid models based on 2 rather than a single metaheuristic have been applied to reservoir and dam water systems [24]. The hybrid particle swarm optimization and artificial fish optimization was used for a single-objective single-reservoir system problem. Establishing proper communication between the algorithms constitutes a major challenge in developing the hybrid models [24]. An easily implemented hybrid bat-particle swarm algorithm developed using a certain communication process was inefficient in terms of convergence rate [24]. Moreover, the shortcomings of evolutionary algorithms include being trapped in local optimal points, early convergence, producing immature solutions, and a low convergence rate [26]. Inspired from the social behaviors of humpback whales, Lewis and Mirjalili developed the whale optimization in 2016 as a swarm intelligence algorithm [27]. Inefficiency in examining the entire search space constitutes a major disadvantage of this algorithm. Given the acceptable potential of the differential evolution for exploration [28], the present study developed and implemented the improved whale optimization algorithm as a hybrid whale optimization-differential evolution algorithm in MATLAB and analyzed its application to managing water resources.

\section{Materials and Methods}

3.1. DifferentialEvolution. Despite basic similarities between the differential evolution introduced by [29] and the structure of evolutionary algorithms, their difference lies in the way mutation and crossover are applied in the former to update solutions based on a standard evolutionary algorithm. In fact, the solution vectors randomly selected from the population undergo component swapping, addition, and subtraction before updating the generation. The differential evolution performs mutation as a constant and a weighting factor for differential vectors before crossover and mutation. Differential vectors are calculated as the average of several differential vectors obtained from different randomly selected pairs or the difference between 2 of randomly selected solution vectors from the population. An updated solution vector known as the noisy vector is obtained by adding the weighted difference vector to a solution vector that is selected randomly. The trial vector then obtained through a crossover between the target vector in the population and the noisy vector is ultimately compared to the target vector to pass the better one to the next generation. This process continues to fill up the next generation by the number of newly generated candidate solutions.

The stages of the differential evolution are shown in Figure 1. The randomly selected vectors need to be discriminated from one another. In contrast to genetic algorithm, no selection mechanisms are used in the differential evolution and minimum-cost vectors in minimization problems associated with trial vectors or parent target vectors are advanced to the next generation. The differential evolution is based on $P(G)$ as the population of generation $G$ including $n_{\text {pop }}$ individuals as candidate solutions. Position matrix $P(G)$ is expressed as follows:

$$
P^{(G)}=X_{i}^{G}\left[\begin{array}{ccccccc}
X_{1,1}^{G}, & X_{2,1}^{G}, & X_{3,1}^{G}, & \ldots & \ldots & \ldots & X_{n \mathrm{pop}, 1}^{G} \\
X_{1,2}^{G}, & X_{2,2}^{G}, & X_{3,2}^{G}, & \ldots & \ldots & \ldots & X_{n \mathrm{pop}, 2}^{G} \\
X_{1,3}^{G}, & X_{2,3}^{G}, & X_{3,3}^{G}, & \ldots & \ldots & \ldots & X_{n \mathrm{pop}, 3}^{G} \\
& & \vdots & & & \\
X_{1, n v a r}^{G}, & X_{2, n v a r}^{G}, & X_{3, n v a r}^{G}, & \ldots & \ldots & \ldots & X_{n \mathrm{pop}, n v a r}^{G}
\end{array}\right],
$$

where $G_{\max }$ represents the maximum number of generations defined by users, $n$ var the number of variables or diameters to be selected, $X_{i, j}^{G}$ the $j$ th component, i.e., that is, the $j$ th link diameter, of the $i$ th candidate solution, and $X_{i}^{G}$ the ith candidate solution or individual in the $G$ th generation.

An arbitrarily generated initial population represented as $P(0)$ in the differential evolution is as follows:

$$
\begin{aligned}
P^{(0)} & =X_{i, j}^{(0)}=X_{j}^{(L)}+\operatorname{rand}_{i, j}\left(X_{j}^{(U)}-X_{j}^{(L)}\right) i=1 \text { to } n_{\mathrm{pop}, j} \\
& =1 \text { to } n_{\mathrm{var}},
\end{aligned}
$$

in which $X_{j}^{(L)}$ and $X_{j}^{(U)}$, respectively, represent the lower and upper bounds of variable jand randij a random variable uniformly distributed on $[0,1]$.

Subsequent generations $P^{(G+1)}$ or new vectors are generated successively through mutation as a combination of vectors that are selected randomly from the current population. Afterwards, a predetermined target vector is combined with the noisy vector. Moreover, $P^{(G+1)}$ as the trial vectors population is generated through mutation and recombination as follows:

$$
X_{i, j}^{(G+1)}= \begin{cases}X_{C, j}^{(G)}+F \times\left(X_{A, j}^{(G)}-X_{B, j}^{(G)}\right), & \text { if } \operatorname{rand}_{i, j} \leq C_{r} ; \quad \forall j=D_{i}, \\ X_{i, j}^{(G)}, & \text { otherwise, }\end{cases}
$$

in which $D=1, \ldots \ldots \ldots n_{\text {param }}, A \in\left[1, \ldots \ldots \ldots n_{\text {param }}\right]$, $B \in\left[1, \ldots \ldots \ldots n_{\text {pop }}\right], C \in\left[1, \ldots \ldots \ldots n_{\text {pop }}\right], \quad A \neq B \neq C \neq i$, $C_{r} \in[0$ to 1$] F \in[0$ to 1$]$ rand $\in[0$ to 1$]$. F represents a mutation constant or weighting factor defined by users on $[0$, 1] and $C_{r}$ the minimization problem defined by users. 


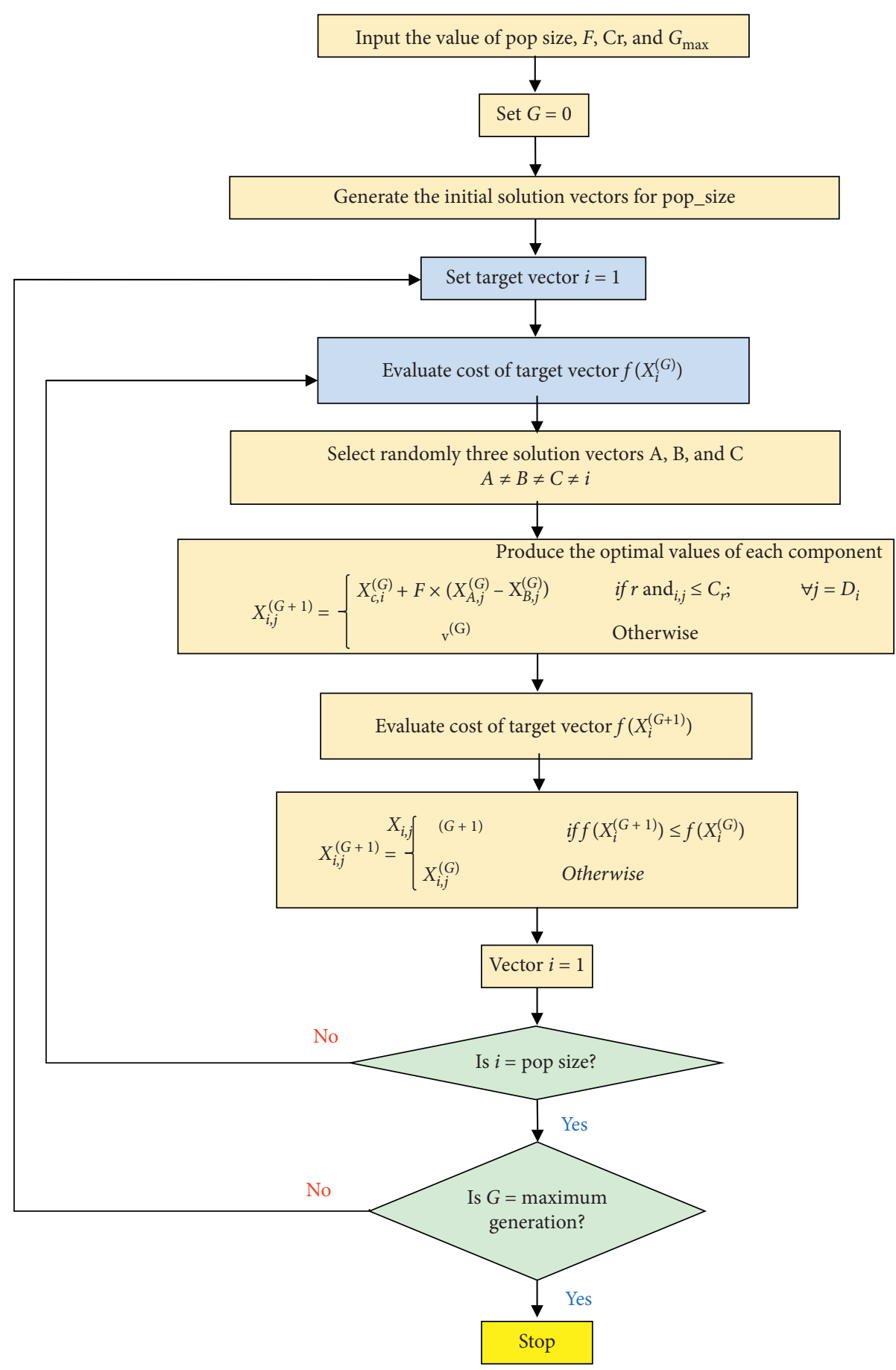

Figure 1: Flowchart of the differential evolution.

Otherwise, the target vector is selected for the following generation, whose population $P^{(G+1)}$ is selected using the following equation:

$$
X_{i, j}^{(G+1)}= \begin{cases}X_{i, j}^{(G+1)}, & \text { if } f\left(X_{i}^{(G+1)}\right) \leq f\left(X_{i}^{(G)}\right), \\ X_{i, j}^{(G)}, & \text { otherwise }\end{cases}
$$

in which $f\left(X_{i}^{(G)}\right)$ denotes the cost of the $i^{\text {th }}$ individual of the $G^{\text {th }}$ generation [30].
The computational modules applied to optimally designing a water distribution network using the differential evolution are shown in Figure 2. Given the proper explorative potential of mutation in the differential evolution, this algorithm can effectively identify the zone of a global optimum despite its inappropriate exploitation [28].

3.2. Whale Optimization Algorithm. In 2016, inspiring from a bubble-net hunting strategy, A. Lewis and Seyed Ali 


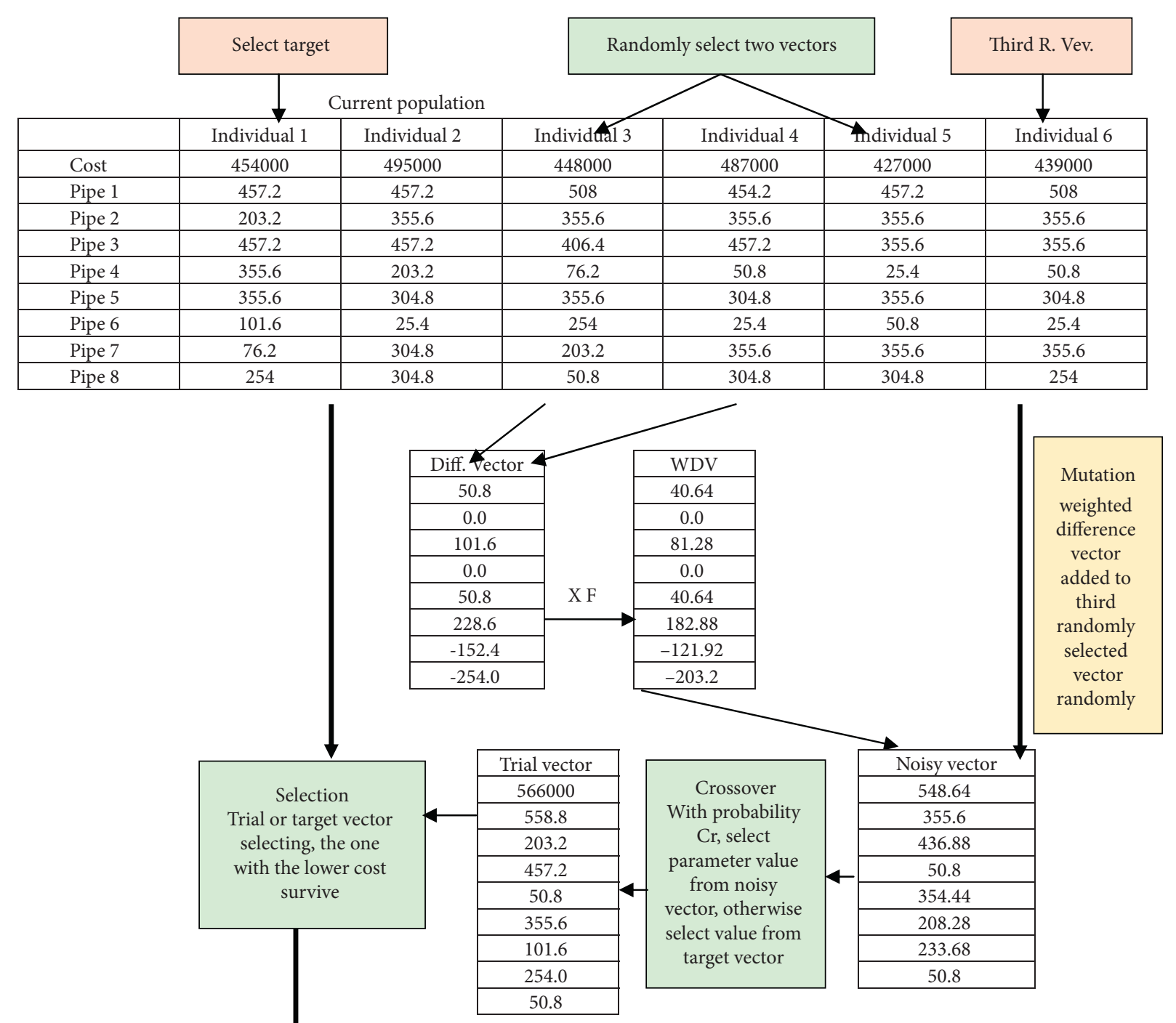

Following generation population

\begin{tabular}{|c|c|c|c|c|c|c|}
\hline & Individual 1 & Individual 2 & Individua 3 & Individual 4 & Individual 5 & Individual 6 \\
\hline Cost & 454000 & & & & & \\
\hline Pipe 1 & 457.2 & & & & & \\
\hline Pipe 2 & 203.2 & & & & & \\
\hline Pipe 3 & 457.2 & & & & & \\
\hline Pipe 4 & 355.6 & & & & & \\
\hline Pipe 5 & 355.6 & & & & & \\
\hline Pipe 6 & 101.6 & & & & & \\
\hline
\end{tabular}

Figure 2: Computational modules applied to optimally design a water distribution network using the differential evolution.

Mirjalil proposed the whale optimization as metaheuristic describing unique hunting behaviors of humpback whales. According to this algorithm, whales follow typical bubbles and create a circular or 9-shaped route while encircling prey during their hunting. The bubble-net feeding/hunting behavior can be explained by the fact that humpback whale go down in water by approximately 10-15 meters followed by producing spiral bubbles encircling the prey while following the bubbles and moving toward the surface. The following expression is 
used to mathematically present the whale optimization algorithm.

3.3. Equation for Encircling a Prey. After encircling small fish as the prey by humpback whales, they update their position towards the optimal solution as the number of iterations is maximized:

$$
\begin{aligned}
\vec{D} & =\left|C \cdot \vec{X}^{*}(t)-X(t)\right|, \\
\vec{X}(t+1) & =\vec{X}^{*}(t)-\vec{A} \cdot \vec{D},
\end{aligned}
$$

in which $X(t)$ represents the vector of position, $\vec{X}^{*}(t)$ the vector of position of the most recent optimal solution, $t$ the current iteration, and $\vec{A}$ and $D$ coefficient vectors which can be calculated as follows:

$$
\begin{aligned}
& \vec{A}=2 r \vec{a}-\vec{a}, \\
& \vec{C}=2 r,
\end{aligned}
$$

where $r$ represents a random value on $[0,1]$ and $\vec{a}$ a linearly decreasing variable from 2 to 0 throughout the iterations.

3.4. Bubble-Net Attacks. Two methods proposed as the mathematical representation of the bubble-net behavior of humpback whales, as illustrated in Figure 3, are as follows.

3.4.1. Shrinking Encirclement. This method is based on a linear decrease from two to zero in $\vec{a}$. The vector random value lies on $[-1,1]$.

3.4.2. Spiral Position Updates. The spiral position between humpback whales and the prey following a helix shape can be mathematically expressed as follows:

$$
\vec{X}(t+1) \vec{D} \cdot e^{b l} \cdot \cos (2 \pi l)+\overrightarrow{X^{*}}(t),
$$

in which $b$ is a constant defining the logarithmic shape, $l$ a random value over $[-1,1]$, and $\vec{D}=\left|X^{*}(t)-X(t)\right|$ the distance between the prey and the ith whale used to update the solution. The probability of the whale following a logarithmic path or perform shrinking encircling during optimization is assumed to be $50 \%$. The related mathematic equation is expressed in the following:

$$
\vec{X}(t+1)= \begin{cases}\overrightarrow{X^{*}}(t)-\vec{A} \cdot \vec{D}, & p<0.5, \\ e^{b t} \cos (2 \pi l) \vec{D}+\overrightarrow{X^{*}}(t), & p \geq 0.5,\end{cases}
$$

with $p$ being a random value over $[0,1]$.

3.4.3. Searching for the Prey. $\vec{A}$ is used to find the prey on the basis of the following 2 conditions while taking values above 1 or below -1 :

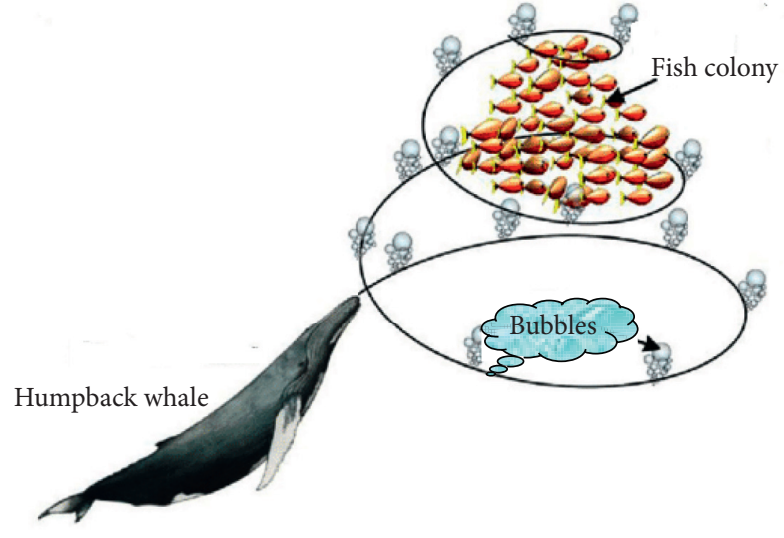

FIGURE 3: Bubble-net behavior based on whale optimization algorithm.

$$
\begin{aligned}
\vec{D} & =\left|C \cdot \overrightarrow{X_{\text {rand }}}-\vec{X}(t)\right|, \\
\vec{X}(t+1) & =\vec{X}_{\text {rand }}-\vec{A} \cdot \vec{D} .
\end{aligned}
$$

The following conditions are ultimately met:

(i) $|\vec{A}|>1$ ensures that traps in local optimal solutions are avoided throughout the search by the whale optimization algorithm.

(ii) $|\vec{A}|<1$ is selected to update the current search agent/ best solution in terms of position [27]. The whale optimization algorithm flowchart is illustrated in Figure 4 .

3.5. Improved Whale Optimization. This section presents improvement in the whale optimization algorithm. The present study integrated the mutation of the differential evolution with the whale optimization algorithm to improve and balance the exploration and exploitation phases and increase its convergence rate. The algorithm proposed is explained as follows.

The trade-off existing between the exploration and exploitation of the whale optimization algorithm was solved in the improved whale optimization algorithm using a hybrid model comprising the operators of this algorithm and the mutation operator of the differential evolution. The main hybrid operator of the improved algorithm (see lines 10-28 of proposed algorithm) is a combination of mutation in the differential evolution and the components of the whale optimization algorithm, namely, encircling prey, search for prey, and spiral updating position. The improved whale optimization algorithm consists of two main parts, that is, exploration (see lines 11-18 of proposed Algorithm) and exploitation (see lines 19-27 of proposed Algorithm). If rand $<k$, the exploration part changes the individuals. Equation (8) was used to adjust $k$.

$$
\lambda=1-\frac{t}{t_{\max }}
$$




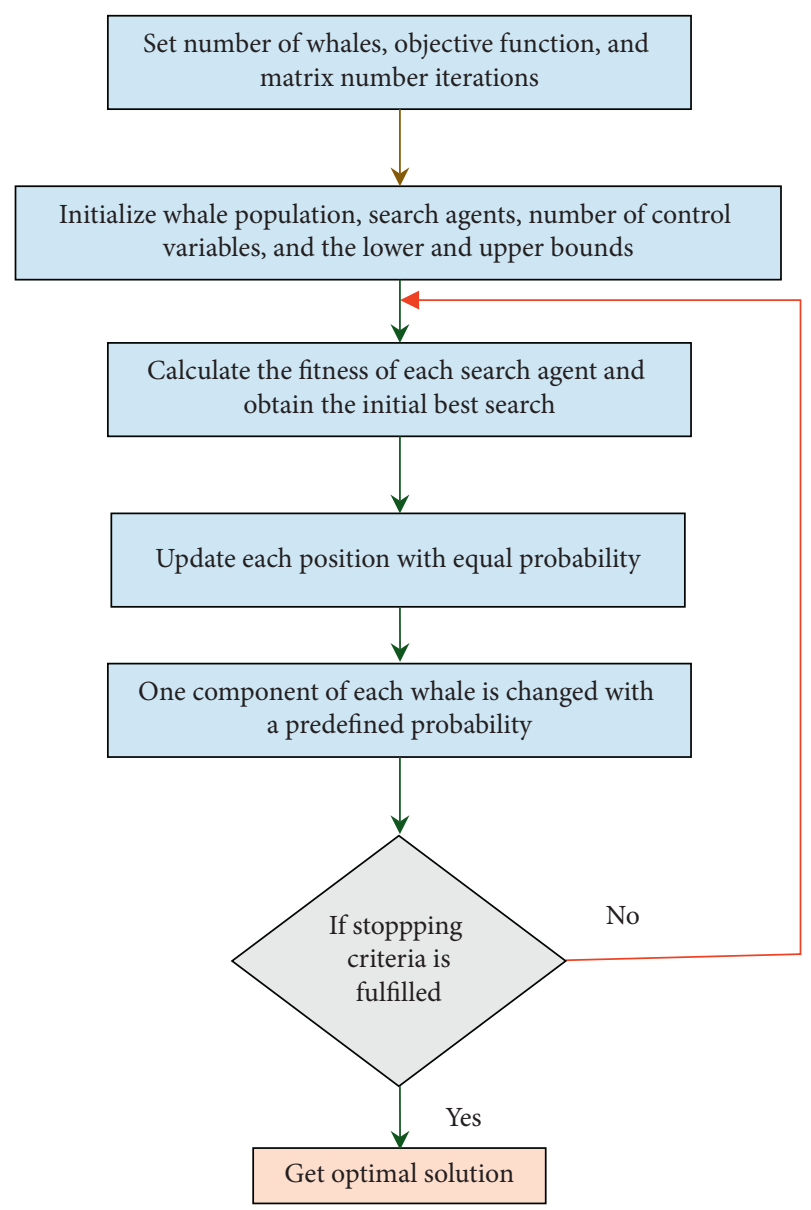

FIgURE 4: Flowchart of whale optimization algorithm.

in which $t_{\max }$ and $t$, respectively, show the maximum number of generations and the current generation and $k$ is utilized to control the exploration and exploitation of the improved whale optimization algorithm. According to (8), decreasing $k$ over time from 1 to 0 allows the individuals to explore the initial generation, while doing exploitation as time passes. The exploration part contains the mutation of the differential evolution and search for the prey of the whale optimization algorithm. The improved algorithm is integrated with mutation to enhance exploration throughout the search space [28]. The exploitation component of the improved whale optimization algorithm resembles that of the whale optimization, although the improved algorithm is an elitist method. In fact, the updated position of the ith individual in the next generation is selected as the fitter one of offspring $U_{i}$ and parent $X_{i}$. The solution is obtained by considering the boundary conditions, which should not be violated; otherwise, the repairing rule is applied according to (9).

$$
X_{i}(j)=\left\{\begin{array}{l}
\delta_{j}+\operatorname{rndreal}(0,1) \times\left(\mu_{j}-\delta_{j}\right) X_{i}(j)<\delta_{j}, \\
\mu_{j}-\operatorname{rndreal}(0,1) \times\left(\mu_{j}-\delta_{j}\right) X_{i}(j)<\mu_{j},
\end{array}\right.
$$

with rndreal $(0,1)$ being a random value between 0 and 1 , $X_{i}(j)$ the $j$ th dimension of the $i$ th solution, while $\delta_{j}$ and $\mu_{j}$, respectively, show the lower and upper limits of the $j$ th dimension.

Improved whale optimization algorithm is as follows.

(1) Generating an initial population $X_{i}, i=1,2, \ldots, N_{P}$

(2) Measuring the individuals fitness in $X_{i}$

(3) Calculating $X^{*}$ as the best individual

(4) While the stopping criterion is not satisfied

(5) Mapping the fitness to the number of species for every individual

(6) For $i=1$ to $N_{P}$

(7) Selecting a uniformly-distributed random value $r 1-r 2-r 3-\mathrm{i}$

(8) Updating $a=2-t\left(2 / t_{\mathrm{Max}}\right), \quad A=2$ ara, $C=2 r, \quad l=$ $\operatorname{rndreal}(-1,1), p=\operatorname{rndreal}(0,1)$ and $k=1-\left(t / t_{\mathrm{Max}}\right)$

(9) $j_{\text {rand }}=\operatorname{rndint}(1, n)$

(10) For $j=1: n$

(11) If $p \_k$ then

(12) If rndreal $j(0,1) \_$CR or $j==j_{\text {rand }}$ then

(13) $U_{i}(j)=X^{*}(j)+F \_\left[X r 2 \cdot(j) \_X r 3(j)\right]$

(14) Else

(15) Selecting the random individual $X_{\text {rand }}$

(16) $D=\left|C \cdot X_{\text {rand }}-X_{i}\right|$

(17) $U_{i}(j)=X_{\text {rand }}(j)-A . D$

(18) End if

(19) Else if $p>k$ then

(20) If rndrealj $(0,1)-0.5$ then

(21) $D=\left|C \cdot X^{*}-X_{i}\right|$

(22) $U_{i}(j)=X^{*}(j)-A \cdot D$

(23) Else

(24) $D=\left|X^{*}-X_{i}\right|$

(25) $U_{i}(j)=D \cdot \operatorname{expbl} \cdot \cos (2 \cdot p i \cdot 1)+X^{*}$

(26) End if

(27) End if

(28) End for

(29) Evaluating the offspring $U_{i}$

(30) If $U_{i}$ is better than $X_{i}$ then

(31) Updating individual $i, X_{i}=U_{i}$

(32) If $U_{i}$ is better than $X^{*}$ then

(33) Updating the best individual $X^{*}=U_{i}$

(34) End if

(35) End if

(36) End for

(37) $t=t+1$

(38) End while

The structure of the proposed improved whale optimization algorithm is simple. The only difference between the improved algorithm and the whale optimization lies in integrating the mutation of the differential evolution with 
the latter algorithm. The selection function of the improved algorithm resembles that of the differential evolution. The improved algorithm therefore computationally resembles the whale optimization based on $O($ MaxGen $\times N p \times$ $O$ (fitness)). The maximum number of generations is denoted as maxgen and $O$ (fitness) is calculated by the application [31]. Figure 5 shows the different stages of the improved whale optimization algorithm.

3.6. Case Study. Boostan is a clay-core Earth dam in northeastern Gonbad-eKavus, Golestan Province, Iran, for satisfying an irrigation demand of 4200 ha of land and environmental and industrial water demand. The dam's length is 665 meters, its top width 10 meters, the minimum storage volume of its reservoir $0.1 \times 10^{6} \mathrm{~m}^{3}$, and the maximum storage volume $43.7 \times 10^{6} \mathrm{~m}^{3}$. According to Figure 6 showing the monthly inputs, the present study was conducted during 151 months from October 2005 to April 2018.

Boostan Reservoir Dam lies in the GorganroodGharasoo Basin as part of the $13061 \mathrm{~km}^{2}$ Caspian Basin in the southeast of the Caspian Sea. Climate change affects the average annual precipitation in the watershed from the east to west and from the north to south. The average annual temperature in this basin ranges from approximately $17^{\circ} \mathrm{C}$ at low altitudes to $7.5^{\circ} \mathrm{C}$ in the southern highland area. The geographical situation of the present research area is illustrated in Figure 7.

Findings obtained from the present case study are recommended to be used by policymakers to satisfy the irrigation demand in agricultural regions. The released water was considered a decision variable, and the water volume should be adequate for supplying the demand of the downstream farmers. The shortage of water was minimized using the following objective function:

$$
\text { minimize } F_{\text {Release }}=\sum_{t=1}^{T}\left(\frac{\mathrm{De}_{t}-\mathrm{Re}_{t}}{\mathrm{De} e_{\max }}\right)^{2},
$$

in which $D e_{\max }$ represents the maximum demand for water during the operation, $\mathrm{Re}_{t}$ is the discharged water, $\mathrm{De}_{t}$ is the required volume, and $F_{\text {Release }}$ is the objective function. The following continuity equation was also considered:

$$
S_{t+1}=Q_{t}+S_{(t)}-\mathrm{Ev}_{(t)}-\mathrm{Sp}_{(t)}=\operatorname{Re}_{(t)},
$$

in which $\mathrm{Sp}_{(t)}$ represents overflow at time $t, \mathrm{Re}_{(t)}$ the discharged water, $\mathrm{Ev}_{(t)}$ evaporation from the reservoir surface, $S_{(t)}$ the reservoir storage volume at time $t$ as well as an input to the reservoir, and $S_{t+1}$ the reservoir storage volume at time $(t+1)$.

The following constraints were applied to overflow from the reservoir:

$$
S_{P_{t}}= \begin{cases}S_{t}+Q_{t}-\mathrm{Re}_{t}-\mathrm{Ev}-S_{\max }, & \text { if } S_{t}+Q_{t}+\mathrm{Re}_{t}-\mathrm{Ev}>S_{\max }, \\ 0, & \text { if } S_{t}+Q_{t}+\mathrm{Re}_{t}-\mathrm{Ev} \geq S_{\max }\end{cases}
$$

The other constraints were as follows:

$$
\begin{aligned}
S_{\min } & \leq S_{t} \leq S_{\max }, \\
\mathrm{Re}_{\min } & \leq \mathrm{Re}_{t} \leq \mathrm{Re}_{\max },
\end{aligned}
$$

in which $\mathrm{Re}_{\min }$ represents the minimum discharge volume of the reservoir, $\mathrm{Re}_{\max }$ the maximum discharge volume, $S_{\min }$ the minimum volume of the reservoir, and $S_{\max }$ its maximum volume. The following penalty functions were included in the objective function to take account of potentially unsatisfied constraints [32].

$$
\begin{aligned}
& \text { Penalty } 1= \begin{cases}\sum_{t=1}^{T}\left(\frac{S_{t}-S_{\min }}{S_{\min }}\right)^{2}, & \text { if } S_{t}<S_{\min }, \\
\sum_{t=1}^{T}\left(\frac{S_{t}-S_{\max }}{S_{\max }}\right)^{2}, & \text { if } S_{t}<S_{\max }, \\
0, & \text { if } S_{\min } \leq S_{t} \leq S_{\max },\end{cases} \\
& \text { Penalty 2 }= \begin{cases}\sum_{t=1}^{T}\left(\frac{\mathrm{Re}_{t}-D_{\min . t}}{D_{\min . t}}\right)^{2}, & \text { if } \mathrm{Re}_{t}<\mathrm{De}_{\min . t}, \\
\sum_{t=1}^{T}\left(\frac{\mathrm{Re}_{t}-D_{\max }}{D_{\max . t}}\right)^{2} & , \text { if } \mathrm{Re}_{t}<\mathrm{De}_{\max . t} \\
0, & \text { if } \mathrm{De}_{\min . t} \leq S_{t} \leq \mathrm{De}_{\max . t} .\end{cases}
\end{aligned}
$$

The indicators used to measure the performance of various algorithms in solving water resource management problems were as follows. The volumetric reliability indicator is defined as the volume of water discharged in the whole period divided by the overall demand for water as follows [33]:

$$
\alpha_{V}=\frac{\sum_{t=1}^{T} \mathrm{Re}_{t}}{\sum_{t=1}^{T} \mathrm{De}_{t}} \times 100
$$

(1) The time-based reliability indicator showing the percentage of time the demand is completely satisfied by the system is expressed as follows [32].

$$
\alpha_{T}=\left(1-\frac{N \text { Def }}{T}\right) \times 100
$$

in which NDef represents the total number of failures that occurs. Higher values of this index suggest a higher system performance.

(2) The vulnerability index refers to the highest failure rate throughout a reservoir operation, with lower values suggesting a higher performance [34]:

$$
\lambda=\operatorname{Max}_{t=1}^{T}\left(\frac{D_{t}-R_{t}}{D_{t}}\right) \times 100 .
$$

(3) The resiliency indicator reflects the recovery rate of a system after failures; for instance, the occurrence of failures in 4 months of a 12-month operation 


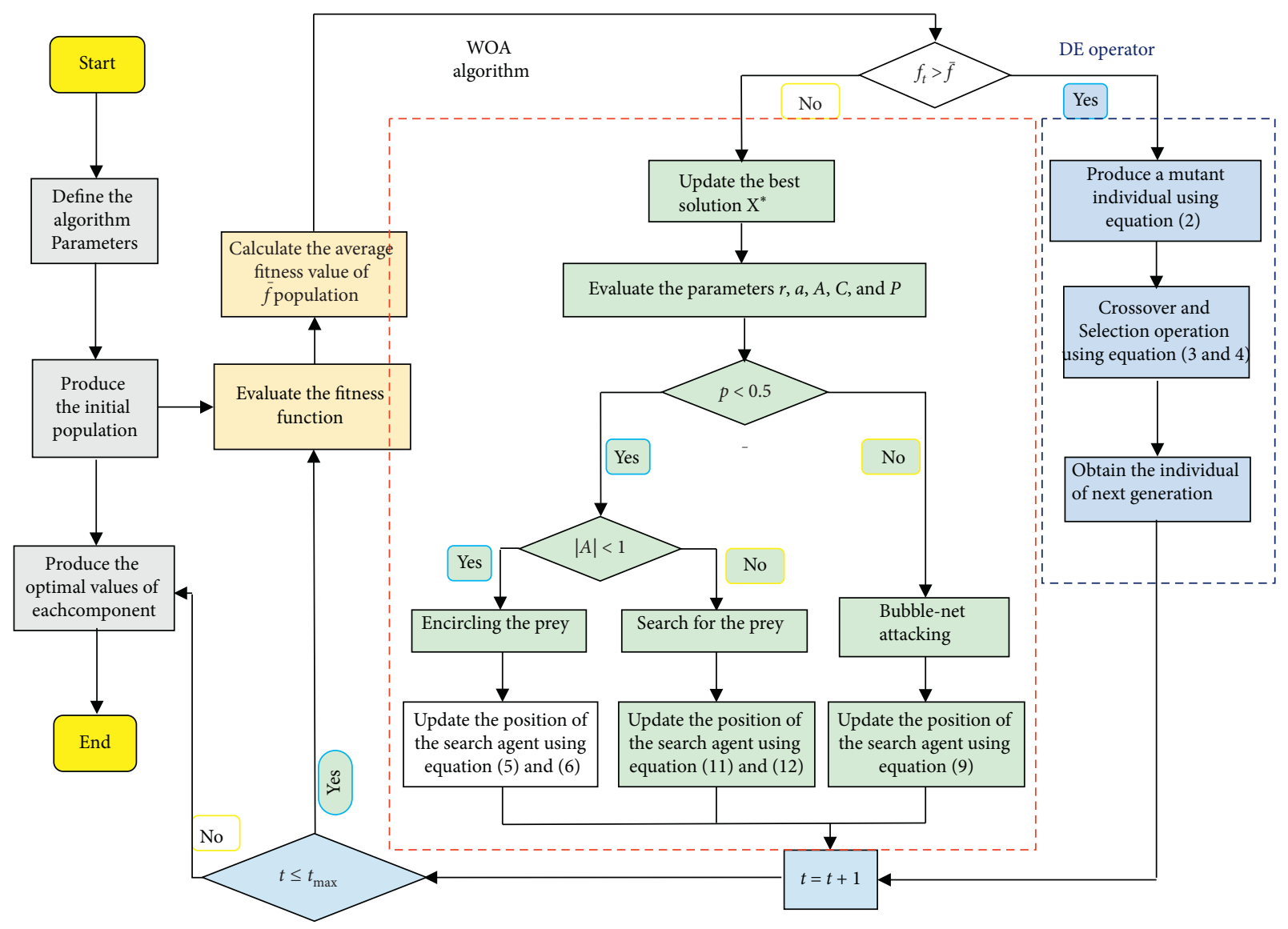

FIGURE 5: Flowchart of improved whale optimization (IWOA).

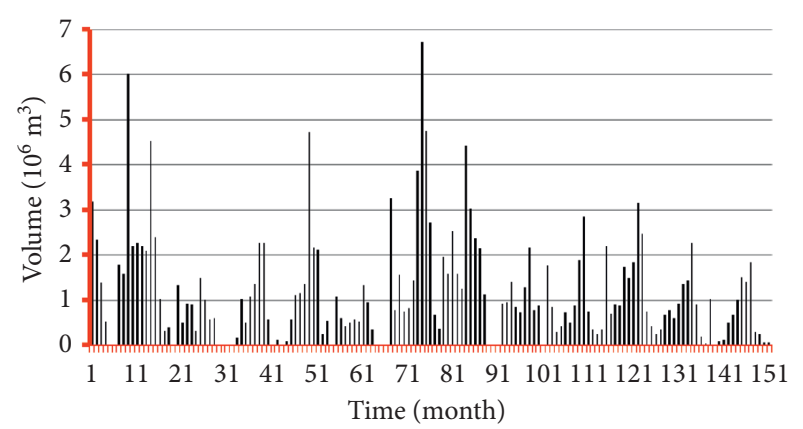

Figure 6: The inflow to Boostan Dam reservoir per month.

suggests the significant effect of the sequence of failure periods on the system. Moreover, larger values of this indicator are more desirable.

$$
\gamma_{i}=\frac{f_{\mathrm{si}}}{F_{i}} \times 100
$$

in which $F_{i}$ represents the total frequency of failure periods and $f_{\mathrm{si}}$ the frequency of occurrence of failure series [26].

(4) The sustainability index defined by performance criteria as follows is defined as the sum of system performance measures in one general index to facilitate comparison and decision-making between different management alternatives and water resources plans $[35,36]$ :

$$
\mathrm{SI}=\left\{\alpha \times \gamma_{i} \times(1-\lambda)\right\}
$$

3.7. Calculating the Weights of the Criteria. Subjective weights were mainly calculated using expert comments according to experiences and subjective judgments such as Delphi and AHP, whereas objective weights were obtained reservoir from actual alternative information associated with techniques, including the entropy weight, which decreases the subjective effect of decision makers and improves objectivity.

As a concept of a thermodynamic origin, entropy was used to calculate system disorders and degree of confusion. Entropy was also used by Shannon to solve information theory problems and resolve uncertainty [37]. The entropy theory suggests lower values of the entropy result in more available data. A higher weight can be therefore assigned to the criterion [38]. Numerous studies have used entropy weight in different fields. The Shannon entropy weight can be calculated through the following steps [39] by assuming a decision matrix with $n$ criteria and $m$ alternatives.

The first stage is normalizing the decision matrix:

$$
n_{j}=\frac{a_{i j}}{\sqrt{\sum_{i=1}^{m} a_{i j}}}, \quad i=1,2, \ldots, m .
$$




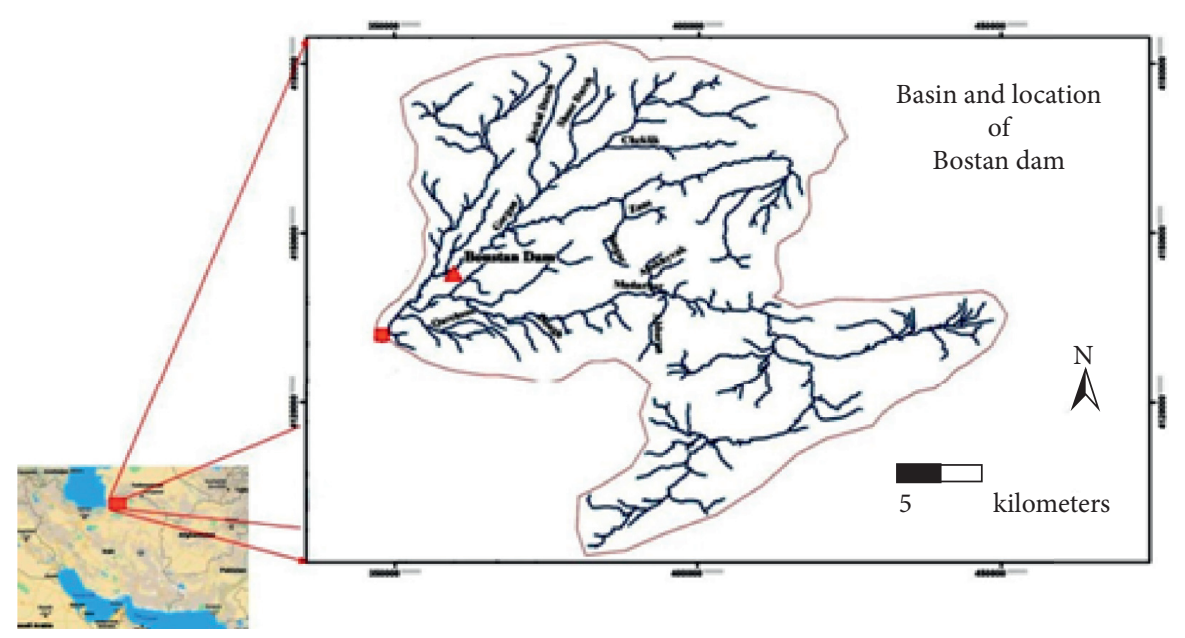

FIgURE 7: The geographical situation of the present study region.

The second stage is calculating entropy:

$$
E_{j}=-K \sum_{i=1}^{m}\left(r_{i j} * \operatorname{Lnr}_{i j}\right), \quad i=1,2, \ldots, n,
$$

in which $K=1 /$ In $m$.

The third stage is calculating the weight of individual criteria:

$$
w_{j}=\frac{1-E_{j}}{\sqrt{\sum_{i=1}^{n}\left(1-E_{j}\right)}}, \quad i=1,2, \ldots, n .
$$

3.8. TOPSIS. Yoon and Hwang proposed TOPSIS as a multicriteria decision-making approach [40] for selecting an optimal alternative. According to the main rule of TOPSIS, the best alternative is, respectively, nearest and farthest from positive ideal and negative ideal solutions [41]. Multicriteria decision-making problems have been commonly solved in numerous fields using this technique. According to Yoon and Huang, the following algorithm is presented for TOPSIS [42].

The first stage is building $R$ as the normalized decision matrix:

$$
r_{i j}=\frac{a_{i j}}{\sqrt{\sum_{i=1}^{m} a_{i j}^{2}}}
$$

The second stage is building the weighted normalized decision matrix:

$$
\begin{aligned}
v_{i j} & =w_{j} r_{i j}, \\
\sum_{j=1}^{n} w_{j} & =1,
\end{aligned}
$$

in which $w_{j}$ represents the $j^{\text {th }}$ criterion weight.

The third stage is obtaining the positive ideal and negative ideal solutions, respectively, shown as $A^{+}$and $A^{-}$as follows:

$$
\begin{array}{ll}
A^{+}=\left\{\left(\min v_{i j} \mid j \in J^{\prime}\right) \operatorname{or}\left(\max v_{i j} \mid j \in J,\right)\right\}, & i=1,2, \ldots, m=\left\{v_{1}^{+},+, \ldots, v_{n}^{+}\right\} \\
A^{-}=\left\{\left(\min v_{i j} \mid j \in J^{\prime}\right) \operatorname{or}\left(\max v_{i j} \mid j \in J\right)\right\}, & i=1,2, \ldots, m=\left\{v_{1}^{-},+, \ldots, v_{n}^{-}\right\}
\end{array}
$$

in which $J$ and $J^{\prime}$, respectively, represents the sets of benefit and cost criteria.

The fourth stage is calculating the distance between individual alternatives and positive ideal and negative ideal solutions:

$$
d_{i}^{+}=\sqrt{\sum_{j=1}^{n}\left(V_{i j}-A_{j}^{+}\right)^{2}}, \quad i=1,2, \ldots, m,
$$

$$
d_{i}^{-}=\sqrt{\sum_{j=1}^{n}\left(V_{i j}-A_{j}^{-}\right)^{2}}, \quad i=1,2, \ldots, m .
$$

The fifth stage is calculating the closeness coefficient and prioritizing the alternatives:

$$
c l_{i}^{*}=\frac{d_{i}^{-}}{d_{i}^{+}+d_{i}^{-}}, \quad 0<c l_{i}^{*}<1,
$$


in which $c l_{i}^{*} \in[0,1], i=1,2, \ldots, m$. An optimal alternative is selected based on the priority of $c l_{i}^{*}$ whose higher values denote a better alternative. The closer the $c l_{i}^{*}$ to unity, the closer the alternative $A_{i}$ to the positive ideal solution.

\section{Discussion}

Tables $1-3$ present the results of a sensitivity analysis on the random variables of various algorithms. The optimal population size was obtained as 60 for the improved whale optimization algorithm with an objective function value of 25.74 being the lowest compared to the other population sizes. The optimal mutation factor $f$ was obtained as 0.4 and the optimal cross over rate $c$ as 0.3 for the differential evolution and its objective function value of 25.84 was found for these two values.

According to Table 4, after randomly running the individual algorithms for ten times, their performance, convergence rate, and statistical parameters were compared with one another and with the absolute optimal values obtained of GAMS as a nonlinear optimization technique. Ten times of running the improved whale algorithm, the differential evolution and the whale optimization algorithm, respectively, resulted in average responses of 25.74, 25.84, and 32.91. The objective function based on the improved whale optimization algorithm therefore minimized water supply shortages. The calculation duration was obtained as 521 seconds for the improved whale algorithm, 527 seconds for the whale optimization algorithm, and 1040 seconds for the differential evolution, suggesting that the improved algorithm yields the minimum computational duration compared to those of the other two algorithms. The lower variation coefficient obtained after running the improved whale algorithm for 10 times compared to that of the other algorithms suggested the adequately reliable results of even one execution of the improved whale algorithm. Although the globally optimal solution obtained with GAMS was 12.553, the hybrid whale optimization outperformed the whale optimization algorithm given that the former improved the performance of the latter by up to $21.7 \%$ in deriving the optimal values of the water supply function through decreasing the variation coefficient by up to $78 \%$ and the standard deviation by up to $82 \%$.

Comparing the three algorithms in terms of convergence rate in Figure 8 showed that the improved whale algorithm convergence is the fastest and therefore outperforms in terms of computation duration and response quality. Replacing a poor solution obtained from an algorithm with a good solution obtained from another algorithm improved the rate of convergence of the improved whale algorithm. In fact, despite the poor individual performance of the differential evolution and the whale optimization algorithm, their hybrid performance was higher.

Given the integration of the mutation operator of the differential evolution with the whale optimization, Figure 8 confirmed the performance of the improved whale algorithm by demonstrating the lower minimum values obtained using this algorithm compared to those obtained from the whale optimization algorithm.

The three algorithms were compared in Table 5 in terms of satisfying the demand for water in the 151-month study
TABLE 1: Sensitivity analyses conducted on the whale optimization and differential evolution and improved whale optimization algorithms.

Hybrid whale optimization algorithm

\begin{tabular}{lcc} 
Population size & Objective function value & Time $(\mathrm{s})$ \\
\hline 20 & 26.92 & 176 \\
40 & 26.03 & 353 \\
60 & 25.74 & 521 \\
80 & 25.96 & 699 \\
\hline
\end{tabular}

TABle 2: Differential evolution.

\begin{tabular}{lcccc}
\hline $\begin{array}{l}\text { Population } \\
\text { size }\end{array}$ & $\begin{array}{c}\text { Mutation } \\
\text { factor }(f)\end{array}$ & $\begin{array}{c}\text { Crossover } \\
\text { rate }(c)\end{array}$ & $\begin{array}{c}\text { Objective } \\
\text { function } \\
\text { value }\end{array}$ & $\begin{array}{c}\text { Time } \\
(\mathrm{s})\end{array}$ \\
\hline 20 & 0.2 & 0.1 & 28.42 & 527 \\
40 & 0.4 & 0.3 & 25.84 & 1040 \\
60 & 0.6 & 0.5 & 27.08 & 1574 \\
80 & 0.8 & 0.7 & 31.62 & 2101 \\
\hline
\end{tabular}

TABle 3: Whale optimization algorithm.

\begin{tabular}{lcc}
\hline Population size & Objective function value & Time $(0)$ \\
\hline 20 & 35.13 & 177 \\
40 & 33.63 & 351 \\
60 & 32.91 & 527 \\
80 & 32.98 & 703 \\
\hline
\end{tabular}

TABLE 4: Results obtained through ten times of randomly running the three algorithms.

\begin{tabular}{lccc}
\hline Run & $\begin{array}{c}\text { Differential } \\
\text { evolution }\end{array}$ & $\begin{array}{c}\text { Whale } \\
\text { optimization }\end{array}$ & $\begin{array}{c}\text { Improved } \\
\text { whale } \\
\text { optimization }\end{array}$ \\
\hline 1 & 26.79 & 34.22 & 25.92 \\
2 & 26.51 & 32.21 & 25.81 \\
3 & 26.41 & 33.75 & 25.78 \\
4 & 24.35 & 33.74 & 25.91 \\
5 & 25.55 & 31.63 & 25.8 \\
6 & 25.63 & 33.56 & 25.68 \\
7 & 26.75 & 32.95 & 25.73 \\
8 & 24.79 & 31.78 & 25.74 \\
9 & 25.05 & 32.68 & 25.65 \\
10 & 26.6 & 32.52 & 25.36 \\
Average & 25.84 & 32.9 & 25.74 \\
Worst response & 26.79 & 34.22 & 25.92 \\
Best response & 24.35 & 31.63 & 25.36 \\
Standard deviation & 0.89 & 0.89 & 0.16 \\
Variation coefficient & 0.034 & 0.027 & 0.006 \\
Nonlinear & & & \\
programming & & 12.553 & \\
minimum value & & & \\
\hline
\end{tabular}

period. The correlation coefficient between the required and actual water discharge obtained as 0.94 for the improved whale algorithm was higher than that of the other algorithms. The root-mean-square errors obtained as $0.72 \times 10^{6} \mathrm{~m}^{3}$ for the improved algorithm, $2.64 \times 10^{6} \mathrm{~m}^{3}$ for 


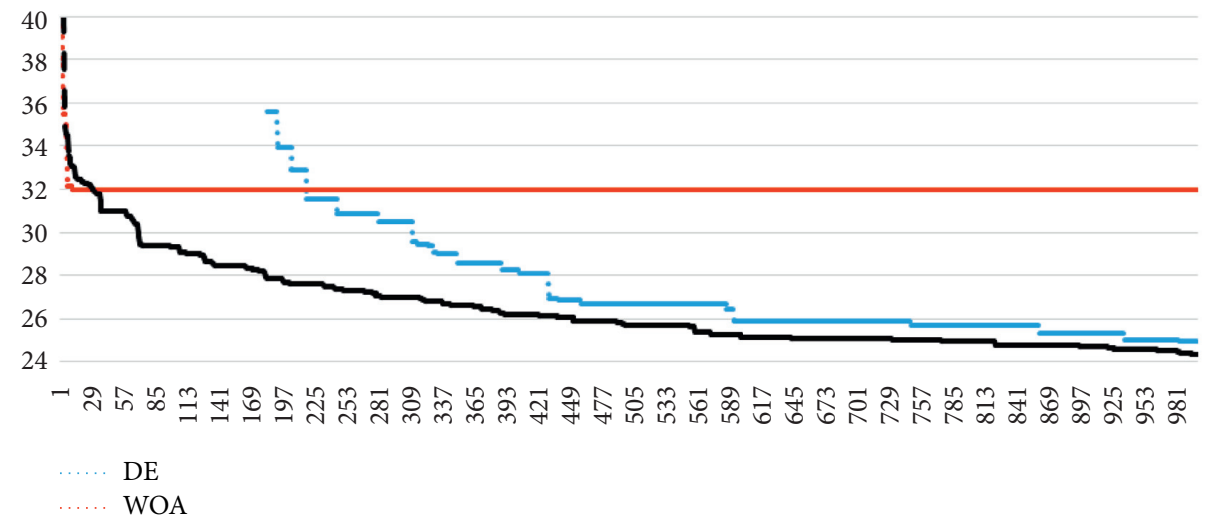

FIgURE 8: Comparing the three algorithms in terms of convergence rate.

TABLE 5: Comparing the different models of supplying demand for water on the basis of statistical indicators.

\begin{tabular}{lcccc}
\hline Index & Nonlinear programming & Differential evolution & Whale optimization & Improved whale optimization \\
\hline Correlation coefficient & 0.96 & 0.53 & 0.61 & 0.94 \\
Root-mean-square error $\left(\mathrm{m}^{3}\right)$ & $1.83 \times 10^{6}$ & $2.64 \times 10^{6}$ & $1.99 \times 10^{6}$ & $0.72 \times 10^{6}$ \\
Mean absolute error & $1.718 \times 10^{6}$ & $2.04 \times 10^{6}$ & $1.223 \times 10^{6}$ & $0.186 \times 10^{6}$ \\
\hline
\end{tabular}

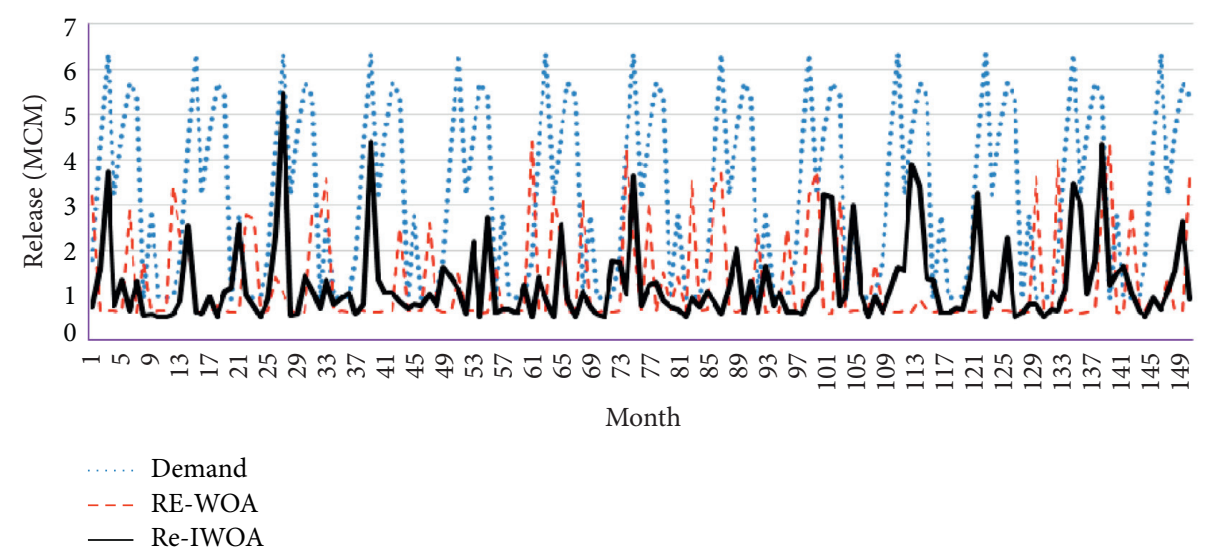

FIGURE 9: Volume of water supplied using the different algorithms.

the differential evolution, and $1.99 \times 10^{6} \mathrm{~m}^{3}$ for the whale optimization algorithm suggested the higher performance of the improved whale optimization algorithm in satisfying demand for water. The lower mean absolute error presented in Table 5 for the improved algorithm compared to that of the other evolutionary algorithms showed that this algorithm outperforms in terms of meeting the downstream demand for water.

With an average demand for water of $3.21 \times 10^{6} \mathrm{~m}^{3}$, Figure 9 shows the improved whale optimization algorithm resulted in a water discharge volume of $3.03 \times 10^{6} \mathrm{~m}^{3}$ from Boostan dam for supplying the demand for the reservoir water over the study period, whereas the differential evolution yielded $1.18 \times 10^{6} \mathrm{~m}^{3}$ and the whale optimization $1.99 \times 10^{6} \mathrm{~m}^{3}$. The improved algorithm was therefore the best algorithm in terms of meeting the demand for water.

Table 6 compares the performance of the study algorithms by the water resources management indicators, suggesting that the improved whale optimization algorithm, with a reliability indicator of $94 \%$, outperformed the other evolutionary algorithms in terms of satisfying the downstream demand for water and with the largest resiliency indicator (89\%) and the minimum objective function (25.74) has the best status. The optimal decision can therefore be made through considering several indicators and using multicriteria decision-making models. In addition to objective function, the other indicators considered in the present case study to select the best algorithm for supplying the downstream water demand included reliability, vulnerability, and resiliency. Comparing the whale optimization algorithm and the improved whale algorithm confirms performance improvements in terms of all the evaluative indicators. Table 7 presents the positive and negative criteria and the criteria weights obtained using the entropy method. The results showed that two criteria, that is, resiliency and time reliability, have, respectively, the highest weights 
TABLE 6: Comparing the evaluative indices obtained using the different optimization algorithms.

\begin{tabular}{lcccccc}
\hline & Volumetric reliability & Time reliability & Resiliency & Vulnerability & Sustainability & Objective function \\
\hline Differential evolution & 0.39 & 0.1 & 0.09 & 0.88 & 0.1 & 26.8 \\
Whale optimization & 0.62 & 0.53 & 0.37 & 0.45 & 0.11 & 0.79 \\
Improved whale & 0.94 & 0.94 & 0.89 & 0.06 & 25.2 & 25.74 \\
\hline & \multicolumn{7}{c}{ Normalized matrix } & 0.6331 & 0.1000 & 0.2000 \\
Differential evolution & 0.2000 & 0.0637 & 0.0667 & 0.1100 & 0.3179 \\
Whale optimization & 0.3175 & 0.3376 & 0.2741 & 0.3237 & 0.7898 & 0.4821 \\
Improved whale & 0.4821 & 0.5987 & 0.6593 & 0.0432 &
\end{tabular}

TABLE 7: Weighted vector of entropy.

\begin{tabular}{lcccccc}
\hline Criterion & Volumetric reliability & Time reliability & Resiliency & Vulnerability & Sustainability & Objective function \\
\hline Positive or negative criteria & Positive & Positive & Positive & Negative & Positive & Negative \\
Weight of criteria & 0.1735 & 0.1809 & 0.1753 & 0.1544 & 0.1477 & 0.1715 \\
Rank & 3 & 1 & 2 & 5 & 6 & 4
\end{tabular}

TABLE 8: Priority of the different algorithms based on TOPSIS.

\begin{tabular}{lcc}
\hline Decision matrix options & Similarity index & Ranking \\
\hline Improved whale optimization algorithm & 0.7585 & 1 \\
Whale optimization algorithm & 0.4730 & 2 \\
Differential evolution & 0.0437 & 3 \\
\hline
\end{tabular}

followed by the other criteria prioritized as the third to the sixth.

The results obtained from TOPSIS on the basis of the decision matrix are shown in Table 8, suggesting that the improved whale optimization algorithm outperformed the other algorithms with the maximum similarity index, whereas the whale optimization and the differential evolution were, respectively, ranked second to third.

\section{Conclusion}

The present research proposed the improved whale optimization as a novel hybrid whale optimization differential evolution algorithm to optimize the operation of Boostan dam reservoir through satisfying the downstream demand for water by Boostan dam reservoir in Golestan province and reducing the shortage of water using a single-reservoir system. Exploration was performed in the improved algorithm by combining the mutation operator of the differential evolution and the search for prey of the whale optimization algorithm. The convergence rate, performance, and statistical parameters of the three algorithms were compared with one another and with the globally optimal solution obtained from nonlinear programming in GAMS by running the individual algorithms for ten times.

The obtained results confirmed the performance superiority of the improved whale optimization algorithm over the differential evolution with the objective function value of 25.74, minimum computation duration, and fastest convergence. In addition, the improved whale optimization improved the objective function, standard deviation, and variation coefficient by $21.7 \%, 82 \%$, and $78 \%$ compared to those of the whale optimization, respectively. Lower values of mean absolute error and root-mean-square error obtained for the improved algorithm also suggest this algorithm can more effectively help supply the demand for water than the other evolutionary algorithms. Given an average demand for water of $3.21 \times 10^{6} \mathrm{~m}^{3}$ over the 151 -month study period, the improved whale optimization algorithm outperformed the other evolutionary algorithm with a water discharge volume of $3.03 \times 10^{6} \mathrm{~m}^{3}$, which was higher than that of the other algorithms. In other words, the improvements in performance achieved can be explained by the integration of the mutation operator of the differential evolution with the whale optimization in the hybrid algorithm, which caused the mutation operator to search the exploration space more effectively.

A multicriteria decision-making model was utilized based on TOPSIS and the Shannon entropy to identify the optimal algorithm. Calculating the evaluative indicators for the three algorithms suggested that the improved whale optimization algorithm, with a reliability index of 94\%, outperforms the other evolutionary algorithms in terms of meeting the downstream demand for water. This algorithm was also found to be the best in terms of objective function value (25.74) and resiliency index (89\%).The multicriteria decision-making model employed in the present research confirmed the functional superiority of the improved algorithm over the other two algorithms in optimizing the operation of Boostan dam reservoir. Moreover, an increase was observed in the volume of Boostan dam reservoir during the exploitation using the improved whale optimization compared to the whale optimization. In line with the results obtained by Kai et al. [4, 32], the present findings showed the superiority of hybrid algorithms over their constituent algorithms. The effect of climate change on this novel hybrid algorithm is recommended to be examined for multireservoir operation. 


\section{Data Availability}

No data were used to support this study.

\section{Conflicts of Interest}

The authors declare that they have no conflicts of interest.

\section{References}

[1] K. Srinivasan and K. Kumar, "Multi-objective simulationoptimization model for long-term reservoir operation using piecewise linear hedging rule," Water Resources Management, vol. 32, pp. 1901-1911, 2018.

[2] M. Ehteram, H. Karami, S. Farzin, and S. Farzin, "Reservoir optimization for energy production using a new evolutionary algorithm based on multi-criteria decision-making models," Water Resources Management, vol. 32, no. 7, pp. 2539-2560, 2018.

[3] I. Ahmadianfar, A. Adib, and M. Salarijazi, "Optimizing multi-reservoir operation: hybrid of bat algorithm and differential evolution," Journal of Water Resources Planning and Management, vol. 142, no. 2, 2015.

[4] C.-T. Cheng, W.-C. Wang, D.-M. Xu, and K. W. Chau, "Optimizing hydropower reservoir operation using hybrid genetic algorithm and chaos," Water Resources Management, vol. 22, no. 7, pp. 895-909, 2008.

[5] M. H. Afshar, "Large scale reservoir operation by constrained particle swarm optimization algorithms," Journal of HydroEnvironment Research, vol. 6, pp. 75-87, 2012.

[6] K. W. Chau, "A split-step particle swarm optimization algorithm in river stage forecasting," Journal of Hydrology, vol. 346, no. 3-4, pp. 131-135, 2007.

[7] M. H. Afshar, "Extension of the constrained particle swarm optimization algorithm to optimal operation of multi-reservoirs system," International Journal of Electrical Power and Energy Systems, vol. 51, pp. 71-81, 2013.

[8] M. Ehteram, H. Karami, S. F. Mousavi, A. El-Shafie, and Z. Amini, "Optimizing dam and reservoirs operation based model utilizing shark algorithm approach," Knowledge-Based Systems, vol. 122, pp. 26-38, 2017.

[9] E. Fallah-Mehdipour, O. Bozorg Haddad, and M. A. Mariño, "Real-time operation of reservoir system by genetic programming," Water Resources Management, vol. 26, pp. 4091-4103, 2012.

[10] L. Ostadrahimi, M. A. Mariño, and A. Afshar, "Multi-reservoir operation rules: multi-swarm PSO-based optimization approach," Water Resources Management, vol. 26, pp. 407427, 2012.

[11] R. Moeini and M. H. Afshar, "Extension of the constrained ant colony optimization algorithms for the optimal operation of multi-reservoir systems," Journal of Hydroinformatics, vol. 15, no. 1, pp. 155-173, 2013.

[12] Z. Zhang, S. Zhang, Y. Wang, Y. Jiang, and H. Wang, "Use of parallel deterministic dynamic programming and hierarchical adaptive genetic algorithm for reservoir operation optimization," Computers \& Industrial Engineering, vol. 65, no. 2, pp. 310-321, 2013.

[13] O. Bozorg Haddad, M. Moravej, and H. A. Loáiciga, “Application of the water cycle algorithm to the optimal operation of reservoir systems," Journal of Irrigation and Drainage Engineering, vol. 141, no. 5, 2014.

[14] O. Bozorg-Haddad, I. Karimirad, S. Seifollahi-Aghmiuni, and H. A. Loáiciga, "Development and application of the bat algorithm for optimizing the operation of reservoir systems," Journal of Water Resources Planning and Management, vol. 141, no. 8, 2014.

[15] Y. Bolouri-Yazdeli, O. Bozorg Haddad, E. Fallah-Mehdipour, M. A. Mariño, and M. A. Mariño, "Evaluation of real-time operation rules in reservoir systems operation," Water Resources Management, vol. 28, no. 3, pp. 715-729, 2014.

[16] O. Bozorg Haddad, S. M. Hosseini-Moghari, and H. A. Loáiciga, "Biogeography-based optimization algorithm for optimal operation of reservoir systems," Journal of Water Resources Planning and Management, vol. 142, 2015.

[17] H. R. Asgari, O. Bozorg Haddad, M. Pazoki, and H. A. Loáiciga, "Weed optimization algorithm for optimal reservoir operation," Journal of Irrigation and Drainage Engineering, vol. 142, 2015.

[18] H. Akbari-Alashti, O. Bozorg Haddad, and M. A. Mariño, "Application of fixed length gene genetic programming (FLGGP) in hydropower reservoir operation," Water Resources Management, vol. 29, pp. 3357-3370, 2015.

[19] O. Bozorg-Haddad, M. Janbaz, H. A. Loáiciga, and H. A. Loáiciga, "Application of the gravity search algorithm to multi-reservoir operation optimization," Advances in Water Resources, vol. 98, pp. 173-185, 2016.

[20] M. Ehteram, M. F. Allawi, H. Karami et al., "Optimization of chain-reservoirs' operation with a new approach in artificial intelligence," Water Resources Management, vol. 31, pp. 2085-2104, 2017.

[21] S. F. Mousavi, H. R. Vaziri, H. Karami, and O. Hadiani, "Optimizing reservoirs exploitation with a new crow search algorithm based on a multi-criteria decision-making model," JWSS, vol. 22, pp. 279-290, 2018.

[22] H. Karami, S. F. Mousavi, S. Farzin, M. Ehteram, V. P. Singh, and O. Kisi, "Improved krill algorithm for reservoir operation," Water Resources Management, vol. 32, pp. 3353-3372, 2018.

[23] M. Ehteram, S. F. Mousavi, H. Karami et al., "Reservoir operation based on evolutionary algorithms and multi-criteria decision-making under climate change and uncertainty," Journal of Hydroinformatics, vol. 20, pp. 332-355, 2018.

[24] Z. M. Yaseen, H. Karami, M. Ehteram et al., "Optimization of reservoir operation using new hybrid algorithm," KSCE Journal of Civil Engineering, vol. 22, pp. 4668-4680, 2018.

[25] A. Donyaii, A. Sarraf, and H. Ahmadi, "Water reservoir multiobjective optimal operation using Grey Wolf optimizer," Shock and Vibration, vol. 2020, Article ID 8870464, 10 pages, 2020.

[26] M. Valikhan-Anaraki, S.-F. Mousavi, S. Farzin et al., "Development of a novel hybrid optimization algorithm for minimizing irrigation deficiencies," Sustainability, vol. 11, no. 8, p. 2337, 2019.

[27] S. Mirjalili and A. Lewis, "The whale optimization algorithm," Advances in Engineering Software, vol. 95, pp. 51-67, 2016.

[28] W. Gong, Z. Cai, and C. X. Ling, "DE/BBO: a hybrid differential evolution with biogeography-based optimization for global numerical optimization," Soft Computing, vol. 15, no. 4, pp. 645-665, 2011.

[29] R. Storn and K. Price, "Differential evolution-a simple and efficient adaptive scheme for global optimization over continuous spaces," Technical Report, International Computer Science Institute, Berkeley, CA, USA, 1995.

[30] C. R. Suribabu, "Differential evolution algorithm for optimal design of water distribution networks," Journal of Hydroinformatics, vol. 12, no. 1, pp. 66-82, 2010. 
[31] S. M. Bozorgi and S. Yazdani, "IWOA: an improved whale optimization algorithm for optimization problems," Journal of Computational Design and Engineering, vol. 6, pp. 243-259, 2019.

[32] M. Mohammadi, S. Mousavi, S. Farzin, and H. Karami, "Optimal Operation of Salman Farsi dam reservoir using Wall algorithm and its hybrid with genetic algorithm based on multi criteria Decision," Eco Hydrology Journal, vol. 6, no. 2, pp. 281-293, 2019.

[33] M. Ehteram, H. Karami, S.-F. Mousavi, S. Farzin, and O. Kisi, "Evaluation of contemporary evolutionary algorithms for optimization in reservoir operation and water supply," Journal of Water Supply: Research and Technology-Aqua, vol. 67, no. 1, pp. 54-67, 2017.

[34] M. Ehteram, H. Karami, S.-F. Mousavi, S. Farzin, and O. Kisi, "Optimization of energy management and conversion in the multi-reservoir systems based on evolutionary algorithms," Journal of Cleaner Production, vol. 168, pp. 1132-1142, 2017.

[35] B. A. Lane, S. Sandoval-Solis, and E. C. Porse, "Environmental flows in a human-dominated system: integrated water management strategies for the Rio Grande/Bravo basin," River Research and Applications, vol. 31, no. 9, pp. 1053-1065, 2014.

[36] S. Sandoval-Solis, D. C. McKinney, D. P. Loucks, and D. P. Loucks, "Sustainability index for water resources planning and management," Journal of Water Resources Planning and Management, vol. 137, no. 5, pp. 381-390, 2011.

[37] Z. H. Zou, Y. Yun, and J. N. Sun, "Entropy method for determination of weight of evaluating indicators in fuzzy synthetic evaluation for water quality assessment," Journal of Environmental Sciences, vol. 18, no. 5, pp. 1020-1023, 2006.

[38] J. Ye, "Fuzzy decision-making method based on the weighted correlation coefficient under instuitionistic fuzzy environment," European Journal of Operational Research, vol. 205, no. 1, pp. 202-204, 2010.

[39] F. H. Lotfi and R. Fallahnejad, "Imprecise Shannon's entropy and multi attribute decision making," Entropy, vol. 12, no. 1, pp. 53-62, 2010.

[40] C. L. Hwang and K. Yoon, "Methods for multiple attribute decision making," in Multiple Attribute Decision Making. Lecture Notes in Economics and Mathematical SystemsVol. 186, Springer, Berlin, Germany, 1981.

[41] N. Chitsaz and M. E. Banihabib, "Comparison of different multi criteria decision-making models in prioritizing flood management alternatives," Water Resources Management, vol. 29, no. 8, pp. 2503-2525, 2015.

[42] M. Uneyama, J. K. Chambers, K. Nakashima, K. Uchida, and H. Nakayama, "Histological classification and immunohistochemical study of feline colorectal epithelial tumors," Veterinary Pathology 2011 Multiple Attribute Decision Making: Methods and Applications, Chapman and Hall/CRC, Boca Raton, FL, USA, 2020. 